\title{
DISPERSÃO E PERSISTÊNCIA DE LEGUMINOSAS FORRAGEIRAS TROPICAIS APÓS INGESTÃO POR BOVINOS
}

\author{
DISPERSION AND PERSISTENCE OF LEGUMINOUS TROPICAL FORAGE AFTER \\ INGESTION BY CATTLE
}

\begin{abstract}
João Carlos de Carvalho ALMEIDA ${ }^{1}$; Tatiana Oliveira da SILVA ${ }^{2}$; Delci de Deus NEPOMUCENO ${ }^{3}$; Norberto Silva ROCHA ${ }^{2}$; Raphael Pavesi ARAÚJO²; Tatiana Pires PEREIRA ${ }^{2}$; Mirton José Frota MORENZ ${ }^{4}$ João Batista Rodrigues de ABREU ${ }^{1}$

1. Zootecnista, Professor Associado Instituto de Zootecnia da Universidade Federal Rural do Rio de Janeiro, (IZ/UFRRJ), Seropédica, RJ, Brasil. joaocarlosbq@gmail.com; 2. Zootecnista, discente do curso de Pós-graduação em Zootecnia da UFRRJ (PPGZ/UFRRJ); 3. Médico veterinário, discente do curso PPGZ/UFRRJ; 4. Zootecnista, Pesquisador A da Empresa Brasileira de Pesquisa Agropecuária, Gado de Leite (CNPGL), Juiz de Fora, MG - Brasil.
\end{abstract}

\begin{abstract}
RESUMO: Entre os fatores determinantes da baixa utilização do consórcio gramínea-leguminosa, pode ser citado a implantação das leguminosas em pastagens já estabelecida. No entanto, animais podem servir como mecanismo de dispersão das sementes. Assim, objetivou-se neste estudo avaliar a introdução das leguminosas calopogônio, macrotiloma, kudzu tropical e soja perene em pastagem estabelecida de Brachiaria decumbens, por meio da dispersão em fezes de bovinos. Para esta finalidade, foi utilizado cinco novilhas como veiculadoras das sementes, as quais foram ofertadas $180 \mathrm{~g}$ de sementes de cada leguminosa misturado ao concentrado de forma alternada, esperando um período de $48 \mathrm{~h}$ para completa defecação das sementes. Todas as leguminosas foram encontradas nas placas fecais, porém o kudzu tropical apresentou maior número de exemplares encontrados em relação às demais $(\mathrm{P}<0,05)$. Quando avaliada a persistência após estabelecimento e pastejo, foi encontrado menor número de exemplares para o kudzu tropical em relação às outras três leguminosas $(\mathrm{P}<0,05)$, que não diferiram entre si. No entanto, a porcentagem de sementes germinadas nas fezes em relação à quantidade de sementes ofertadas em $180 \mathrm{~g}$ de sementes para este mecanismo de propagação pode ser considerado baixo para as quatro leguminosas estudadas.
\end{abstract}

PALAVRAS-CHAVE: Calopogônio. Kudzu tropical. Macrotiloma. Soja perene.

\section{INTRODUÇÃO}

A pecuária brasileira caracteriza-se pela exploração extensiva das pastagens, sendo estas geralmente formadas por gramíneas (ALMEIDA et al., 2002; AROEIRA et al., 2005). Neste contexto, a adoção de sistema de consórcio gramíneasleguminosas é uma alternativa que visa o incremento da produtividade animal (DIAS et at., 2007). Esta estratégia de manejo integra a produtividade das gramíneas ao alto valor nutricional e a fixação biológica de nitrogênio (FBN) proporcionado pelas leguminosas forrageiras ao sistema (BARCELLOS et al., 2008). Outro fator considerado neste tipo de manejo é a presença de sistema radicular pivotante das leguminosas, capaz de captar nutrientes (FÁVERO et al., 2000) e água de camadas mais profundas do solo, em comparação com as gramíneas (GRIEU et al., 2001), que possuem sistema radicular fasciculado. Este mecanismo proporciona melhor distribuição da produção de forragem durante o ano, em quantidade e qualidade adequadas às exigências nutricionais de animais com alto potencial genético, promovendo, ainda, melhor proteção ao solo, evitando a erosão e lixiviação dos nutrientes (OLIVEIRA et al., 2009).
Porém, a introdução de leguminosas em pastagens estabelecidas apresenta uma série de dificuldades, dentre as quais podem ser citados custo de aquisição de sementes, baixa persistência da leguminosa, manejos específicos e adubação inadequadas (EUCLIDES et al., 1998).

Adicionados a estes fatores deve ser levado em consideração a dormência das sementes de leguminosas, fenômeno pelo qual as sementes de uma determinada espécie, mesmo sendo viáveis e tendo todas as condições ambientais favoráveis à germinação, deixam de germinar (COSTA et al., 2010), o que atrasa a formação do pasto, e que está associado à presença de um tegumento espesso, impermeável à água (JACOB JUNIOR et al., 2004) que tem que ser quebrada para acelerar e estabelecer crescimento uniforme das leguminosas (RIBAS et al, 1996).

Entretanto, existe na natureza forma de propagação de sementes pelos próprios animais, dentre as quais se destacam o transporte das sementes presas aos pelos e nos cascos, denominada de dispersão ectozoocoria, e a realizada pelos animais ao defecarem sementes ingeridas durante $o$ forrageamento da planta, conhecida por dispersão endozoocoria (JANZEN, 1982). Esta segunda forma 
pode beneficiar a introdução de leguminosas em locais de difícil manejo ou acesso, e que são pastejados por bovinos.

A dispersão de sementes realizadas por ruminantes promove, além da distribuição espacial com baixo custo, uma escarificação (quebra da dormência) devido à passagem pelo trato digestório (CARMONA, 1992), o que submete as sementes à ação dos microrganismos e ácidos do rúmen, ação mecânica proporcionada pelos movimentos de ruminação, e ação dos ácidos digestivos.

Jolaosho et al. (2006) estudaram três espécies de ruminantes (caprinos, ovinos e bovinos) como agentes dispersores de sementes de plantas forrageiras através de suas fezes e encontraram melhor resultado para os ovinos e caprinos $(28 \mathrm{e}$ $32 \%$ de germinação das sementes), respectivamente, em oposição as sementes dispersadas por bovinos, que apresentaram apenas $5 \%$ de germinação.

Sementes de estilosantes contidas em fezes de bovinos apresentam baixa taxa de germinação. Porém este fato foi associado à baixa viabilidade da técnica para a introdução da espécie na pastagem (REZENDE et al., 2007). Porém, Deminicis et al. (2009) ao avaliarem a germinação de sementes de leguminosas forrageiras tropicais em fezes de bovinos, após a sua passagem pelo trato digestório, mostraram que a técnica pode ser uma opção para a sua dispersão e formação de pastagens consorciadas com gramíneas. Estes diferentes resultados podem ser influenciados pelas sementes das próprias leguminosas que apresentam características peculiares a cada espécie, e a alimentação fornecida aos animais no momento da ingestão das sementes, que influencia a sobrevivência das sementes no trato digestivo.

Devido o exposto, objetivou-se neste trabalho avaliar a introdução das leguminosas calopogônio (Calopogonium mucunoides), macrotiloma (Macrotyloma axillare), kudzu tropical (Pueraria phaseoloides) e soja perene (Neonotonia wightii) em pastagem já estabelecida de Brachiaria decumbens, por meio da dispersão e germinação de suas sementes através das fezes de bovinos.

\section{MATERIAL E MÉTODOS}

O estudo foi conduzido na Fazenda "Campo Alegre" localizada no município de Barbacena, MG - Brasil $\left(21^{\circ} 14^{\prime} \mathrm{S}\right.$ e $43^{\circ} 44^{\prime} \mathrm{W}, 1.164$ metros de altitude) no período de janeiro de 2007 a maio de 2008. O solo da área experimental apresentou as seguintes características na camada de $0-20 \mathrm{~cm}$ : $\mathrm{Ca}^{++} 2,8 \mathrm{cmol}_{\mathrm{c}} / \mathrm{dm}, \mathrm{Mg}^{++} 2,1 \mathrm{cmol}_{\mathrm{c}} / \mathrm{dm}^{3}, \mathrm{Al}^{+++} 0,09$ $\mathrm{cmol}_{\mathrm{c}} / \mathrm{dm}^{3}, \mathrm{P} 1,2 \mathrm{mg} / \mathrm{L}, \mathrm{K} 14,2 \mathrm{mg} / \mathrm{L}, \mathrm{C}_{\text {org }} 1,74 \%$, V $51 \%$ e pH 5,5. A precipitação pluviométrica no período experimental foi de $1.330 \mathrm{~mm}$ e os dados referentes às temperaturas máximas e mínimas estão apresentados na figura 1 .

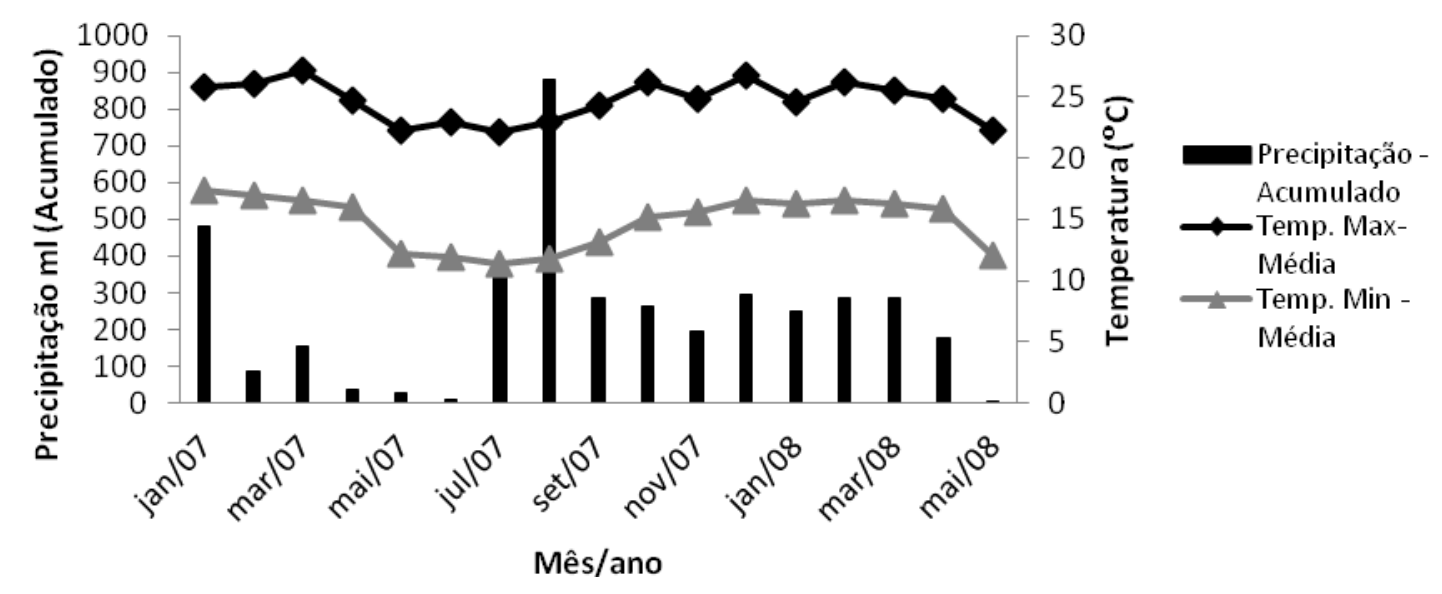

Figura 1. Médias mensais das temperaturas (máximas e mínimas) e precipitação durante período experimental para município de Barbacena, MG - Brasil. Fonte: Estação Meteorológica de Barbacena.

$\mathrm{O}$ estudo foi conduzido em delineamento inteiramente casualizado com quatro tratamentos (leguminosas) utilizando novilhas como dispersoras de sementes por meio da defecação. As novilhas, holandês $\mathrm{x}$ zebu $(\mathrm{n}=5)$, utilizadas neste trabalho apresentaram peso médio de $250 \mathrm{~kg}$, sendo oferecidos $180 \mathrm{~g}$ de sementes de leguminosa por animal misturado ao concentrado (composto por quirela de milho e farelo de soja, com $18 \%$ de PB), a cada $48 \mathrm{~h}$, de forma que cada animal ingerisse uma espécie diferente.

Foram utilizados piquetes como (unidades experimentais) $(\mathrm{n}=5)$ de 0,2 ha cada, para o pastejo das novilhas e propagação das sementes. 
As sementes foram fornecidas aos animais individualmente, e após 24 horas após remoção dos animais dos piquetes, foi realizada uma avaliação segundo a metodologia proposta por Deminicis (2005), que consistiu na marcação das fezes encontrada em cada piquete por meio de estacas coloridas feitas com bambus, de acordo com a leguminosa ofertada.

Os animais permaneceram 48 horas em cada piquete de $B$. decumbens, período este determinado para a completa defecação das sementes das leguminosas ingeridas (DEMINICIS, 2005). Em seguida foi reofertada a cada novilha $180 \mathrm{~g}$ de uma segunda leguminosa, sendo as novilhas encaminhadas a um diferente piquete, sendo este mecanismo realizado até que as cinco novilhas ingerissem sementes de todas as leguminosas e percorressem os cinco piquetes disseminando as sementes em suas fezes. Após isto, as novilhas foram retiradas da área.

Após remoção dos animais e com as placas de fezes identificadas por espécies de leguminosas, teve início o período de avaliação quanto à germinação e persistência das leguminosas. A primeira avaliação ocorreu em março de 2007 (60 dias após introdução das novilhas aos piquetes) a segunda, terceira e quarta avaliações ocorreram em outubro (266 dias), fevereiro (330dias) e maio (470 dias), respectivamente. Em cada avaliação, foi obtido o número médio de plantas de cada espécie de leguminosas por placa fecal ou no local marcado com estacas de bambu devido decomposição da placa fecal.

A avaliação de germinação foi realizada no mês de março, período anterior a entrada de animais $(\mathrm{n}=5)$ novilhas, que permaneceram por um período de 2 dias em cada piquete. Após este período a área foi vedada ao pastejo para recuperação da forragem até o mês de outubro, devido a condições climáticas adversas da região, que impõem um período de dias, maior que o convencional para reestabelecimento da pastagem (figura 1). Nos meses de outubro de 2007, fevereiro e maio de 2008 foram avaliados a sobrevivência das leguminosas anteriormente a entrada de animais nos piquetes.

A de germinação de cada leguminosa estudada foi obtida através da divisão da média do número de plantas pelo número de placas fecais.

A de persistência foi avaliada utilizando a equação: persistência $=\mathrm{n}^{\circ}$ de plantas observada (terceira e quarta avaliações) $/ \mathrm{n}^{0}$ de plântulas observada em março, sendo os valores dispostos em forma de número médios de plantas.

Os resultados obtidos foram submetidos à análise de variância (teste F) e, aplicando-se o teste de Tukey no nível de 5\% de probabilidade para comparação das médias, através do programa estatístico SAS versão 9.1 (SAS INSTITUTE, 2006).

\section{RESULTADOS E DISCUSSÃO}

O número de placas fecais com plantas de leguminosas diferiu entre as espécies $(\mathrm{P}<0,05)$, sendo que as placas marcadas que deveriam conter sementes de calopogônio foram inferiores ao número de placas marcadas para kudzu tropical e macrotiloma, em função da excreção de fezes diferenciada dos animais na pastagem no período avaliado (Tabela 1).

Tabela 1. Número (médio) de placas fecais marcadas de acordo com as leguminosas ofertadas às novilhas e em janeiro que apresentaram plantas (média e porcentagem (\%)) em março

\begin{tabular}{|c|c|c|c|}
\hline \multirow[t]{3}{*}{ Leguminosa } & \multicolumn{3}{|c|}{ Período de avaliação } \\
\hline & \multirow[t]{2}{*}{ Janeiro } & \multicolumn{2}{|c|}{ Março } \\
\hline & & & $\% * *$ \\
\hline Kudzu tropical & $7,2 \pm 1,47 \mathrm{Aa}^{*}$ & $5,8 \pm 1,01 \mathrm{Aa}$ & $80,5 \%$ \\
\hline Macrotiloma & $7,4 \pm 1,03 \mathrm{Aa}$ & $4,0 \pm 1,22 \mathrm{ABb}$ & $35,1 \%$ \\
\hline Soja perene & $6,0 \pm 0,84 \mathrm{ABa}$ & $2,2 \pm 0,48 \mathrm{Bb}$ & $42,3 \%$ \\
\hline Calopogônio & $4,2 \pm 1,07 \mathrm{Ba}$ & $2,6 \pm 1,17 \mathrm{Ba}$ & $50,0 \%$ \\
\hline
\end{tabular}

*Médias seguidas de mesma letra não diferem entre si, maiúscula na coluna e minúscula na linha, pelo teste de Tukey $(\mathrm{P}<0,05)$.

** Porcentagens de placas encontradas no mês de março em relação às encontradas no mês de janeiro.

$\mathrm{Na}$ contagem das placas fecais em março, ocorreu diminuição de placas marcadas para sementes de macrotiloma e soja perene $(\mathrm{P}<0,05)$ em relação ao mês de janeiro, fato este que pode está relacionado ao conteúdo de água, condições climáticas, época e atividade da fauna do solo (GILLET et al., 2010).

Na tabela 2 estar representado o número de plantas encontradas nos períodos avaliados 
Tabela 2. Número médio de ocorrência (germinação - mês março de 2007) e persistência das leguminosas kudzu tropical, macrotiloma, soja perene e calopogônio nos meses de outubro de 2007 e fevereiro e maio de 2008.

\begin{tabular}{ccccc}
\hline \multirow{2}{*}{ Leguminosa } & \multicolumn{4}{c}{ Período de avaliação } \\
\cline { 2 - 5 } & Março & Outubro & Fevereiro & Maio \\
\hline Kudzu tropical & $133,8 \pm 50,22 \mathrm{Aa}$ & $7,0 \pm 2,30 \mathrm{Bb}$ & $6,4 \pm 2,69 \mathrm{Ab}$ & $10,8 \pm 9,37 \mathrm{Ab}$ \\
\hline Macrotiloma & $53,2 \pm 20,60 \mathrm{Ba}$ & $46,6 \pm 14,71 \mathrm{Aa}$ & $15,2 \pm 5,28 \mathrm{Aa}$ & $37,6 \pm 6,73 \mathrm{Aa}$ \\
\hline Soja perene & $12,8 \pm 3,83 \mathrm{Ca}$ & $1,6 \pm 0,40 \mathrm{Ba}$ & $16,8 \pm 9,00 \mathrm{Aa}$ & $21,8 \pm 9,11 \mathrm{Aa}$ \\
\hline Calopogônio & $39,0 \pm 23,12 \mathrm{BCa}$ & $17,8 \pm 9,06 \mathrm{Aba}$ & $5,2 \pm 2,74 \mathrm{Aa}$ & $22,4 \pm 8,66 \mathrm{Aa}$ \\
\hline
\end{tabular}

*Médias seguidas de mesma letra não diferem estatisticamente, maiúsculas na coluna e minúsculas nas linhas, pelo teste de Tukey $(\mathrm{P}<0,05)$.

No primeiro período de avaliação, referente ao mês de março, verificou-se a superioridade no número de plantas por placas fecais (média $=133,8$ plântulas) do kudzu tropical $(\mathrm{P}<0,05)$ em relação às demais leguminosas que apresentaram juntas (média de 32,6) plântulas por placas fecais, além de marcar o baixo número de sementes germinadas de soja perene, nas placas fecais em relação ao kudzu tropical e macrotiloma.

A avaliação no mês de outubro foi realizada após um período de escassez hídrica correspondendo aos meses de abril, maio e junho, seguido por período propício (chuvoso) correspondente aos meses de julho e agosto (Figura 1). Nesta avaliação, foi observada maior persistência do macrotiloma e calopogônio, em relação às demais leguminosas $(\mathrm{P}<0,05)$, as quais não diferiram entre si. No entanto, este período foi marcado por um intenso desaparecimento dos exemplares da leguminosa contados em março.

A superioridade do macrotiloma no mês de outubro corrobora com os dados obtidos por Vilela (2005), que encontrou padrão de resposta semelhante e justificou que esta leguminosa apresenta alta tolerância à seca. Enquanto, o calopogônio é citado como uma leguminosa persistente à estação seca (BARCELOS et al., 2008) e caracterizado como leguminosa tolerante à seca (CORREIA et al., 2012).

Já o desempenho da soja perene pode ser explicado pela maior exigência quanto à fertilidade do solo e necessidade de maior período tempo para o seu estabelecimento (VILELA, 2005). O baixo desempenho do kudzu tropical pode ser relacionado à exigência média - alta de fertilidade do solo e à baixa persistência (BARCELLOS et al., 2008). Estes resultados também podem ter sido influenciados pelo tempo de permanência no rúmen e mastigação, além da posição das sementes na placa fecal, que pode ter contribuído para o insucesso da germinação das sementes.

Após avaliação no mês de outubro, houve a inclusão de novilhas $(\mathrm{n}=5)$ aos piquetes contendo as leguminosas. A avaliação da composição botânica realizada em fevereiro e em maio foi proposta para avaliar a persistência das leguminosas ao pastejo e pisoteio, obtendo a manutenção do resultado encontrado em outubro antes da inclusão de animais aos piquetes.

O estádio de plântula é a fase decisiva para a sobrevivência de um indivíduo e para a distribuição espacial de uma população, pois uma espécie somente é capaz de ocupar de maneira permanente um habitat no qual o indivíduo supere os estádios mais sensíveis do ciclo da vida (LARCHER, 2004). As leguminosas estudadas apresentaram este comportamento, o que pode ser relacionado às avaliações iniciadas em período de clima favorável, e seguidos por modificações ambientais, o que influenciou negativamente a germinação e perpetuação destas leguminosas.

Houve diferença $(\mathrm{P}<0,05)$ entre as médias das sementes germinadas nas placas de fezes (Tabela 3). Mesmo assim, este resultado ficou aquém dos resultados apontados por Deminicis et al. (2009), que encontraram para a soja perene, calopogônio e macrotiloma índice de germinação igual a 7,77; 9,25 e 12,38, respectivamente, após ingestão por bovinos. Jolaosho et al. (2006) encontraram taxa de $5 \%$ de germinação das sementes dispersadas por bovinos, no período chuvoso (junho a setembro) na Nigéria. Estes mesmos autores observaram que sementes disseminadas por cabras e ovelhas apresentaram maior taxa de germinação $(32$ e $28 \%$, respectivamente). 
Tabela 3. Porcentagem de sementes que germinou no teste de germinação e $\%$ de gementes que germinou nas placas fecais

\begin{tabular}{lccc}
\hline Leguminosa & $\begin{array}{c}\mathrm{N}^{0} \text {. de sementes } \\
\text { em } 180 \mathrm{~g}\end{array}$ & $\begin{array}{c}\text { \% de sementes } \\
\text { germinadas } *\end{array}$ & $\begin{array}{c}\% \text { de sementes } \\
\text { germinadas nas placas } \\
\text { fecais } * *\end{array}$ \\
\hline Kudzu tropical & 17460 & 64 & $1,35 \pm 0,54 \mathrm{ab}$ \\
Macrotiloma & 17142 & 84 & $0,34 \pm 0,13 \mathrm{bc}$ \\
Soja perene & 31414 & 60 & $0,06 \pm 0,02 \mathrm{c}$ \\
Calopogônio & 11700 & 31 & $1,64 \pm 0,79 \mathrm{a}$ \\
\hline
\end{tabular}

*Teste de germinação realizado na Universidade do Norte Fluminense Darcy Ribeiro (UENF) através do teste de imersão em água a 80 ${ }^{\circ} \mathrm{C} / 5 \min$.** \% de sementes germinadas nas placas fecais em relação ao teste de germinação, Médias seguidas de mesma letra (na coluna) não diferem estatisticamente entre, pelo teste de Tukey $(\mathrm{P}<0,05)$.

A germinação das sementes das leguminosas analisadas pode estar relacionada, principalmente, com a eficiência da quebra de dormência, através da passagem pelo trato digestivo dos bovinos e pela influência climatológica e nutricional que as leguminosas foram submetidas (JONES; SIMÃO NETO, 1987). Além disso, há presença de compostos tóxicos em fezes bovinas que atuam inibindo a germinação de sementes (HOEKSTRA et al., 2002).
Outro fator que foi observado na distribuição das leguminosas através da dispersão de placas fecais é o número de plantas por placa fecal. O objetivo de inserir as sementes nas dietas para os animais é a dispersão das sementes de forma homogênea nos piquetes, porém foi observada a presença de grande número de plantas em poucas placas fecais, o que contraria o objetivo do método de dispersão por animais devido à área de abrangência das fezes (Figura 2).

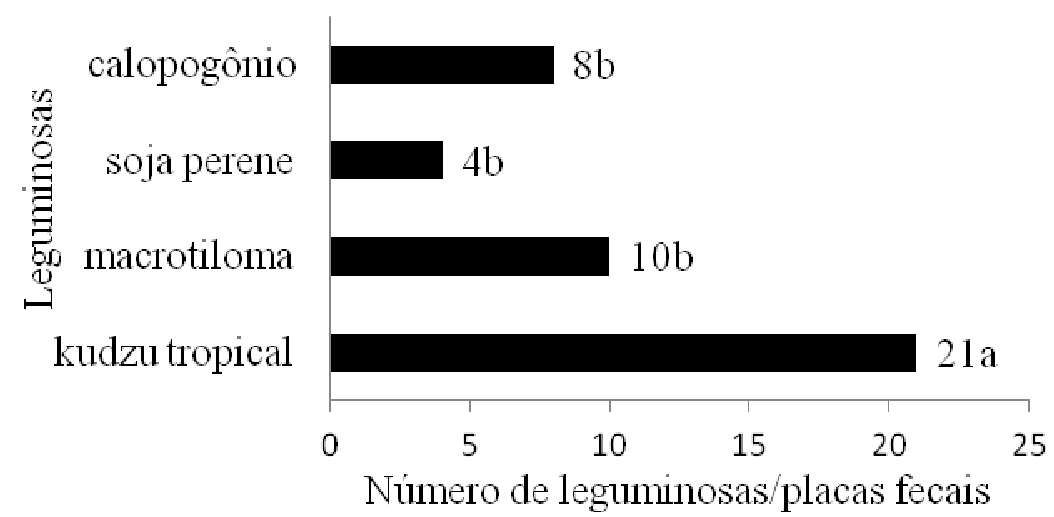

Figura 2. Média geral do número de plantas das leguminosas kudzu tropical, macrotiloma, soja perene e calopogônio, por placa fecal na área experimental.

* Médias seguidas por letras iguais não diferem pelo teste de Tukey $(\mathrm{P}<0,05)$

O estabelecimento das leguminosas depende basicamente da germinação, emergência, penetração da radícula no solo e de seu crescimento inicial. Cada uma destas etapas é dependente de uma série de fatores naturais intrínsecos (longevidade, viabilidade, genótipo, fenótipo, vigor da semente e da plântula) e extrínsecos (propriedades físicas e químicas do solo, microrganismos e clima), determinando $\mathrm{o}$ sucesso ou $\mathrm{O}$ fracasso do crescimento da plântula (PAIVA, 2007). No presente estudo, a qualidade física química do solo não foi fator limitante às leguminosas estudadas.

A passagem pelo trato digestório de bovinos reduziu drasticamente a germinação das sementes das leguminosas estudadas, fator este também relatado por Nakao e Cardoso (2010), que encontraram taxa reduzida de germinação para as leguminosas Leucaena leucocephala (Lam.) de Wit, Cajanus cajan (L.) Huth e Calopogonium mucunoides, ao passar pelo trato digestivo bovino, citando este mecanismo inadequado para a propagação destas leguminosas. Segundo Nakao e Cardoso (2010), este fato ocorre devido ao tamanho e dureza do tegumento das sementes e ao estágio de maturidade dos propágulos além do período de retenção das sementes no intestino. 


\section{CONCLUSÕES}

O método de dispersão de sementes após sua ingestão pode ser utilizado para a introdução de leguminosas por bovinos em pastagens já estabelecidas, entretanto, deve ser utilizado com cautela visto o número de sementes germinadas e de placas fecais.

O macrotiloma, o kudzu tropical, a soja perene e o calopogônio apresentaram baixo potencial para serem dispersos por meio de fezes de bovinos, após sua ingestão.

\section{AGRADECIMENTOS}

Os autores agradecem as empresas Matsuda Sementes e Sementes Selegram pela doação das sementes utilizadas neste experimento.

\begin{abstract}
Among the factors to the low utilization of grass-leguminous intercropping, may be cited the deployment of leguminous in pastures already established. However, animals can serve as a seed dispersal mechanism. Thus, this study aimed to evaluate the introduction of leguminous calopogonium, macrotiloma, tropical kudzu and soybeans, in perennial pastures of Brachiaria decumbens, through dispersal in cattle dung. For this purpose we used five heifers as seeds disseminator, which were offered $180 \mathrm{~g}$ seeds of each leguminous, alternately mixed with the concentrated, waiting a period of 48 hours to complete the seed defecation. All leguminous were found in fecal plates, but kudzu had the greatest number of specimens found in relation to others $(\mathrm{P}<.05)$. However, when evaluated persistence after establishment and grazing found fewer copies to kudzu in the other three leguminous $(\mathrm{P}<0.05)$ that did not differ among themselves. When, the percentage of seeds germinated in the stool, relative to the amount offered in $180 \mathrm{~g}$ of seed for this propagation mechanism, can be considered low for the four leguminous studied.
\end{abstract}

KEYWORDS: Archer. Calopo. Perennial soybean. Puero.

\title{
REFERÊNCIAS
}

ALMEIDA, R. G.; NASCIMENTO JR, D.; EUCLIDES, V. P. B.; MACEDO, M. C. M.; REGAZZI, A. J.; BRÂNCIO, P. A.; FONSECA, D. M.; OLIVEIRA, M. P. Produção animal em pastos consorciados sob três taxas de lotação, no Cerrado. Revista Brasileira de Zootecnia, v. 31, n. 2, 2002. http://dx.doi.org/10.1590/S1516-35982002000400007

AROEIRA, L. J. M.; PACIULLO, D. S. C.; LOPES, F. C. F.; MORENZ, M. J. F.; SALIBA, E. S.; SILVA, J. J.; DUCATTI, C. Disponibilidade, composição bromatológica e consumo de matéria seca em pastagem consorciada de Brachiaria decumbens com Stylosanthes guianensis. Pesquisa Agropecuária Brasileira, v. 40, n. 4, p. 413-418, 2005. http://dx.doi.org/10.1590/S0100-204X2005000400014

BARCELLOS; A. O.; RAMOS, A. K. B.; VILELA, L.; MARTHA JUNIOR, G. B.; Sustentabilidade da produção animal baseada em pastagens consorciadas e no emprego de leguminosas exclusivas, na forma de banco de proteína, nos trópicos brasileiros. Revista Brasileira de Zootecnia, v. 37, p. 51-67, 2008. http://dx.doi.org/10.1590/S1516-35982008001300008

BRAZ, S. P.; NASCIMENTO Jr., D.; CANTARUTTI, R. B.; MARTINS, C. E.; FONSECA, D. M.; BARBOSA, R. A. Caracterização da distribuição espacial das fezes por bovinos em uma pastagem de Brachiaria decumbens. Revista Brasileira de Zootecnia, v. 32, n. 4, 2003. http://dx.doi.org/10.1590/S151635982003000400002

CARMONA, R. Problemática e manejo de bancos de sementes de invasoras em solos agrícolas, Planta Daninha, v. 10, p. 5-16, 1992. http://dx.doi.org/10.1590/S0100-83581992000100007

CORREIA, N. M.; FUZITA, W. E.; DANIEL, B. Cultivo consorciado de milho com amendoim forrageiro e calopogônio e os efeitos na cultura da soja em rotação. Semina: Ciências Agrárias, v. 33, n. 2, p. 575-586, 2012. http://dx.doi.org/10.5433/1679-0359.2012v33n2p575 
COSTA, P. A.; LIMA, A. L. S.; ZANELLA, F.; FREITAS, H. Quebra de dormência em sementes de Adenanthera pavonina L. Pesquisa Agropecuaria Tropical, v. 40, n. 1, p. 83-88, 2010.

DEMINICIS, B. B. Germinação de leguminosas forrageiras tropicais sob tratamentos químicos, físicos e biológicos, 47f. Dissertação (Mestrado em Zootecnia) - Programa de Pós-Graduação em Zootecnia, Universidade Federal Rural do Rio de Janeiro, 2005.

DEMINICIS, B. B.; ALMEIDA, J. C. C.; MALAFAIA, P. A. M.; BLUME, M. C.; ABREU, J. B. R.; VIEIRA, H.D. Germinação de sementes em placas fecais bovinas. Archivos de Zootecnia, v. 58, n. 22, p. 73-8, 2009.

DIAS, P. F.; SOUTO, S. M.; RESENDE, A. S.; URQUIAGA, S.; ROCHA, G. P.; MOREIRA, J. F.; FRANCO, A. A. Transferência do $\mathrm{N}$ fixado por leguminosas arbóreas para o capim Survenola crescido em consórcio. Ciência Rural, v. 37, n. 2, p. 352-356, 2007. http://dx.doi.org/10.1590/S0103-84782007000200009

FAVERO, C.; JUCKSCH, I.; COSTA, L. M.; ALVARENGA, R. C.; NEVES, J. C. L. Crescimento e acúmulo de nutrientes por plantas espontâneas e por leguminosas utilizadas para adubação verde. Revista Brasileira de Ciência do Solo, v. 24, n. 5, p. 171-177, 2000. http://dx.doi.org/10.1590/S0100-06832000000100019

GILLET, F.; KOHLER, F.; VANDENBERGHE, C.; BUTTLER, A. Effect of dung deposition on small-scale patch structure and seasonal vegetation dynamics in mountain pastures. Agriculture, Ecosystems and Environment, v. 135, p. 34-41, 2010. http://dx.doi.org/10.1016/j.agee.2009.08.006

GRIEU, P.; LUCERO, D. W.; ARDIANI, R.; EHLERINGER, J. R. The mean depth of soil water uptake by two temperate grassland species over time subjected to mild soil water deficit and competitive association.

Plant and Soil, v. 230, p. 197-209, 2001. http://dx.doi.org/10.1023/A:1010363532118

HOEKSTRA, N. J.; BOSKER, T.; LANTINGA, E. A. Effects of cattle dung from farms with different feeding strategies on germination and initial root growth of cress (Lepidium sativum L.). Agriculture, Ecosystems and Environment, v. 93, p. 189-196, 2002. http://dx.doi.org/10.1016/S0167-8809(01)00348-6

JACOB JR, E.A.; MENEGHELLO, G.E.; MELO, P.T.B.S.; MAIA, M.S. Tratamentos para superação de dormência em sementes de cornichão anual. Revista Brasileira de Sementes, v. 26, n. 2, p.15-19, 2004. http://dx.doi.org/10.1590/S0101-31222004000200003

JANZEN, D. H. Differential seed survival and passage rates in cows and horses, surrogate Pleistocene dispersal agents. Oikos, v. 38, p. 150-156, 1982. http://dx.doi.org/10.2307/3544014

JOLAOSHO, A. O.; OLANITE, J. A.; ONIFADE, O. S.; OKE, A. O. Seed in the faeces of ruminant animals grazing native pastures under semi-intensive management in Nigeria. Tropical Grasslands, n. 40, p. 79-83, 2006.

JONES, R. M.; SIMÃO NETO, M. The effects of the amount of seed in the diet and of diet quality on seed recovery from sheep. Australian Journal of Experimental Agriculture, v. 27, p. 247-251, 1987.

http://dx.doi.org/10.1071/EA9870253

LARCHER, W. Ecofisiologia Vegetal. Editora Rima. São Carlos - SP. 531 p. 2004.

OLIVEIRA, I. P.; COSTA, K. A. P.; FAQUIN, V.; MACIEL, G. A.; NEVES, B. P.; MACHADO, E. L. Efeitos de fontes de cálcio no desenvolvimento de gramíneas solteiras e consorciadas. Ciência e Agrotecnologia, v. 33, n. $2,2009$.

NAKAO, E. A.; CARDOSO, V. J. M. Recuperação e resposta germinativa de sementes de leguminosas passadas pelo trato digestório bovino. Biota Neotropica, v. 10, n. 3, p. 189-195. 2010.

http://dx.doi.org/10.1590/S1676-06032010000300022 
PAIVA, A. S. Disponibilidade hídrica na germinação de sementes e no crescimento de plântulas da leguminosa forrageira Macrotyloma axillare (E. Mey) Verdc. cv. Java. Tese (Doutorado em Agronomia) - Faculdade de Ciências Agrárias e Veterinárias - UNESP, Jaboticabal. 2007.

PBQP - PROGRAMA BRASILEIRO DA QUALIDADE E PRODUTIVIDADE. Regras para Análise de Sementes, Ministério da Agricultura e Reforma Agrária - Brasília. 51 p. 1992.

REZENDE, A. V.; VILELA, H. H.; PEREIRA, R. S. A.; NOGUEIRA, D. A.; LANDGRAF, P. R. C.; VIEIRA, P. F. Germinação de sementes de Stylosanthes misturadas ao sal para bovinos. II Congresso de Forragicultura e Pastagens. UFLA/NEFOR. Lavras - MG. 2007.

RIBAS, L. L. F.; FOSSATI, L. C.; NOGUEIRA A. C. Superação da dormência de sementes de Mimosa bimucronata (DC.) O. Kuntze (maricá). Revista Brasileira de Sementes, v. 18, n. 1, p. 98-101, 1996.

VILELA, H. Pastagem: Seleção de plantas forrageiras - Implantação e adubação. Editora Aprenda Fácil, Viçosa - MG. 283 p, 2005. 